Muthian S, et al. J Orthop Muscular Syst Res 3: 117.

www.doi.org/10.29011/JOMSR-117.100017

open Oaccess

www.gavinpublishers.com

\title{
Modified Supine Position for Pediatric Elbow Supracondylar Fracture Fixation
}

\section{S Muthian ${ }^{1 *}$, S F Girgis ${ }^{2}$, B Balbisi ${ }^{1}$, D Makki ${ }^{1}$}

${ }^{1}$ Orthopaedic Unit, Watford General Hospital, West Hertfordshire, UK

${ }^{2}$ Orthopaedic Unit, Royal Bournemouth Hospital, Bournemouth, UK

*Corresponding author: S Muthian, Orthopaedic Unit, Watford General Hospital, West Hertfordshire, UK

Citation: Muthian S, Girgis SF, Balbisi B, Makki D (2021) Modified Supine Position for Pediatric Elbow Supracondylar Fracture Fixation. J Orthop Muscular Syst Res 3: 117. DOI: 10.29011/JOMSR-117.100017

Received Date: 27 November, 2021; Accepted Date: 20 December, 2021; Published Date: 23 December, 2021

\section{Background}

Supracondylar fractures make up nearly $18 \%$ of all paediatric fractures [1]. Closed pinning, introduced by Swenson in 1948 is the most common treatment for displaced Gartland Type II and III fractures [2]. The commonest position is supine, with the child's body along the edge of the table and arm either on the hand table or just on the C-arm. Lateral and prone positions have also been described [3].

\section{Technique}

We propose a modified supine position with the child's body on the far edge of the operating table and the injured elbow over the middle of the operating table (Figure 1).

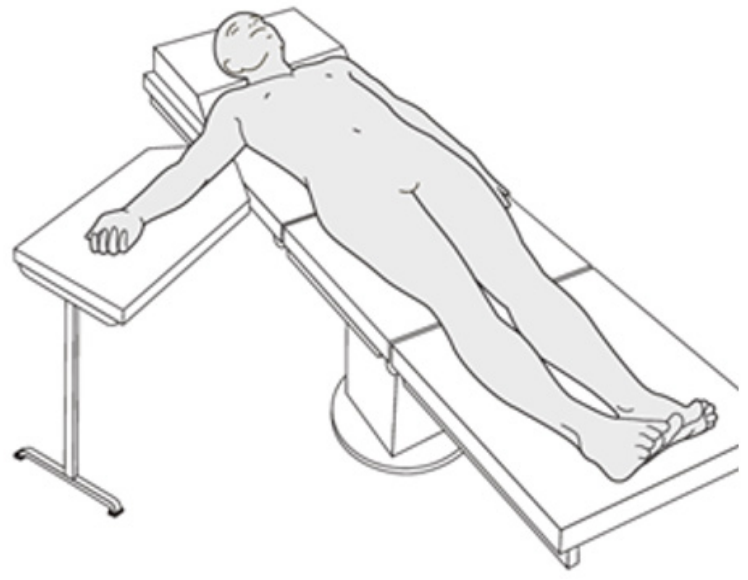

Figure 1: Traditional supine position.

\section{Discussion}

The traditional supine position presents the following difficulties: With traction, the child's head is often pulled over the edge of the table. The operating table may have a radiopaque bar, which interferes with imaging. Inadequate space is available for the assistant and scrub nurse as the $\mathrm{C}$-arm needs to come in from the same side as that of the injured arm (Figure 2).

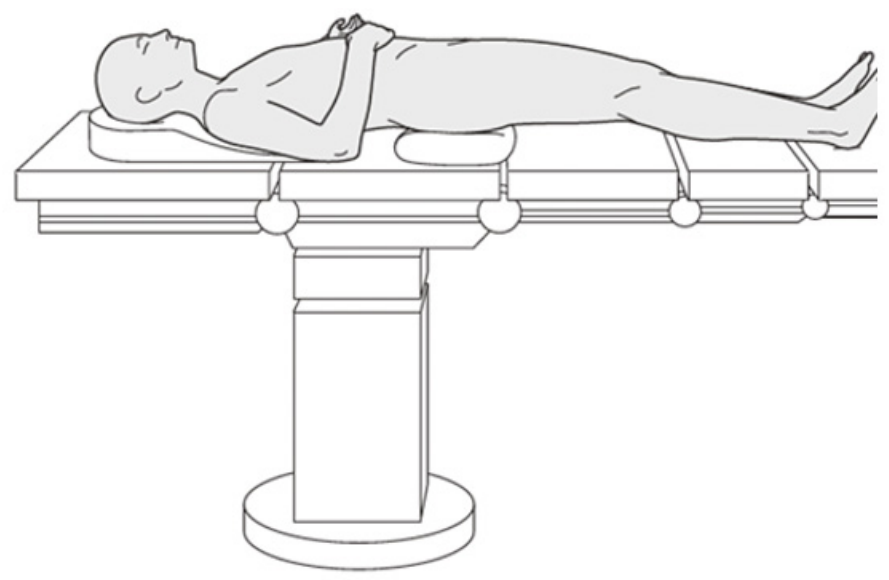

Figure 2: Modified supine positioning-representative image.

The modified position overcomes all these issues and provides adequate space for the assistant and nurse as the $\mathrm{C}$-arm can approach from the contralateral side. The radiopaque bar is avoided. The risk of pulling the head and neck over the edge of the table is also minimised. We utilise this method in our orthopaedic 
unit with successful reduction in the setup time as well as operating time compared to the traditional position (Figures 3 and 4).

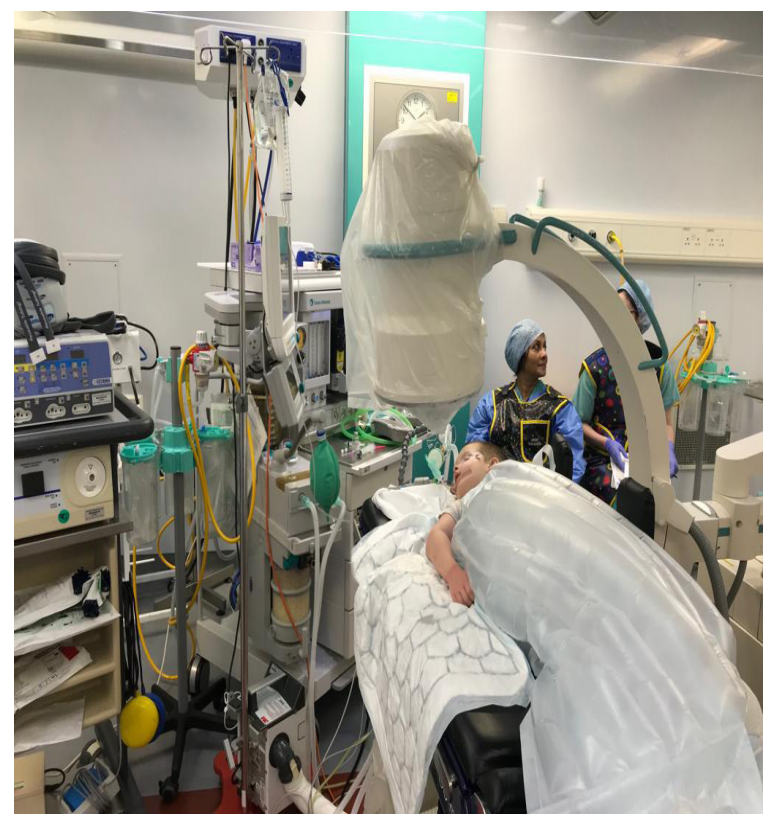

Figure 3: Modified supine position-intra operative appearance.

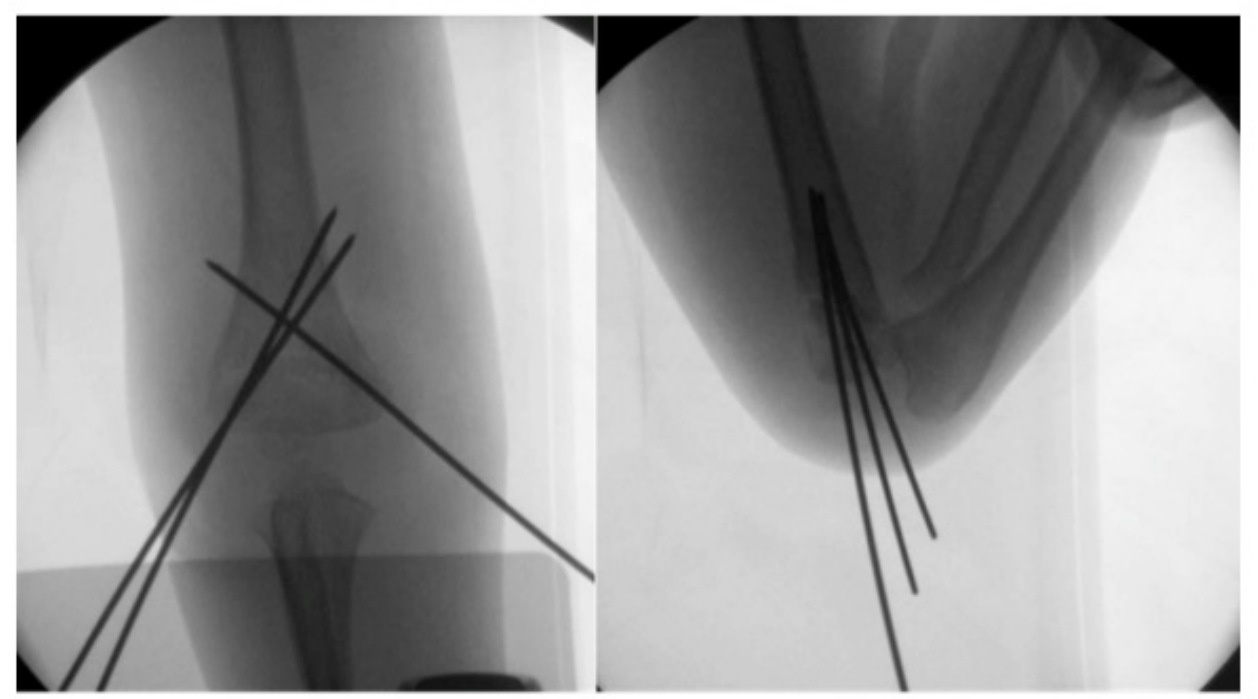

Figure 4: Intra operative images with modified position (Note that there is no interference of metal bar from the side of the table)

\section{References}

1. Mitchelson AJ, Illingworth KD, Robinson BS, Elnimeiry KAK, Wilson CJ, et al. (2013) Patient demographics and risk factors in pediatric distal humeral supracondylar fractures. Orthopedics 36: e700-e706.

2. Swenson AL (1948) The treatment of supracondylar fractures of the humerus by Kirschner-wire transfixion. J Bone Joint Surg Am 30 : $993-997$.

3. Fowler TP, Marsh JL (2006) Reduction and pinning of pediatric supracondylar humerus fractures in the prone position. J Orthop Trauma $20: 277-281$. 